\title{
COMPARATIVE STUDY OF SERUM LDH, URIC ACID AND ALKALINE PHOSPHATASE IN PREECLAMPSIA VERSUS NORMOTENSIVE PREGNANT WOMAN
}

\author{
Suman Umeshchandara Gurugunti1, Syeda Sarah ${ }^{2}$ \\ ${ }_{1}^{1}$ Professor, Department of Obstetrics and Gynaecology, M. R. Medical College, Gulbarga. \\ 2Junior Resident, Department of Obstetrics and Gynaecology, M. R. Medical College, Gulbarga.
}

ABSTRACT

\section{BACKGROUND}

Our aim is to compare the serum levels of Lactate Dehydrogenase (LDH), alkaline phosphatase and uric acid in preeclampsia versus normotensive pregnant woman and correlate their levels with the severity of the disease.

\section{MATERIALS AND METHODS}

100 antenatal patients having preeclampsia and equal no. of normotensive patients were chosen. About 3 mL of blood was drawn under aseptic precautions from selected subjects in a plain vial for serum. Serum was separated by centrifugation and used for estimation of serum levels of LDH alkaline phosphatase and UA.

\section{RESULTS}

We have observed significant difference in serum LDH, alkaline phosphatase and uric acid in hypertensive group patients in comparison with normotensive patients.

\section{CONCLUSION}

We conclude that serum LDH, ALP, Serum Uric Acid are reliable and inexpensive markers to predict severity and maternal and foetal outcome in preeclampsia.

\section{KEYWORDS}

LDH, Uric Acid, Hypertensive Disorders, Alkaline Phosphatase.

HOW TO CITE THIS ARTICLE: Gurugunti SU, Sarah S. Comparative study of serum LDH, uric acid and alkaline phosphatase in preeclampsia versus normotensive pregnant woman. J. Evolution Med. Dent. Sci. 2016;5(97):7146-7150, DOI: 10.14260/jemds/2016/1617

\section{BACKGROUND}

Pregnancy is a physiological state associated with many alterations in metabolic, biochemical, physiological, haematological and immunological processes. If there are no complications, all these changes are reversible following a few days to a few months after delivery. . $2,3^{2}$

Hypertension during pregnancy is a major health problem. It is one of the leading causes of perinatal morbidity and mortality. Preeclampsia (PE) is a theoretical disease with a pathogenesis that is not clearly understood yet. Lately, vascular system pathology and vasoconstriction have been blamed as causes for preeclampsia. ${ }^{4,5}$

During early pregnancy, there is increased body fat accumulation associated with increased lipogenesis, while in late pregnancy there is accelerated breakdown of fat depots which play an important role in foetal development. Early pregnancy dyslipidaemia is associated with an increased risk of preeclampsia. Several studies have been carried out till date to understand the pathophysiological basis of this disease. But still the exact pathophysiology of this disease is not known.

Financial or Other, Competing Interest: None.

Submission 20-07-2016, Peer Review 26-08-2016,

Acceptance 02-09-2016, Published 05-12-2016.

Corresponding Author:

Dr. Suman Umeshchandara,

Laparoscopy Hospital,

Venkatesh Nagar, Gulbarga.

E-mail: drsumanumesh69@gmail.com

DOI: $10.14260 /$ jemds/2016/1617
Lactate Dehydrogenase (LDH) is mainly an intracellular enzyme. It is responsible for interconversion of pyruvate and lactate in the cells. Its levels are several times greater inside the cells than in the plasma. Uric Acid (UA) is an end product of purine metabolism. It is filtrated through the glomeruli and almost completely reabsorbed in the Proximal Convoluted Tubules (PCT) by both active and passive carrier-mediated processes. It is also actively secreted into the tubules; $85 \%$ of total excreted UA is derived by tubular secretion. Hyperuricaemia is found to be one of the earliest laboratory manifestations of preeclampsia. $6,7,8,9$

Alkaline Phosphatase (AP) is known to be produced by the liver, bones, small intestine and kidneys, and different AP isoforms are also expressed by the placenta during pregnancy.

The average amount of AP in one human term placenta amounts to $40 \mathrm{mg}$. The placental isoforms are known as heat stable AP, because they are heat resistant at $60^{\circ} \mathrm{C}$, a property that is the main criterion for distinguishing them from the other isoenzymes.

In early pregnancy, the tissue non-specific AP isoenzyme is mainly expressed in the placenta and reaches a peak value around 10 weeks of pregnancy. At the end of the second trimester, most of the AP activity comprises term placental AP isoenzymes ( $90 \%$ of which are the P1 type, 10\% the P2 type) produced by the syncytiotrophoblasts and these isoenzymes appear in maternal serum between the 15th and 26th weeks of pregnancy. Their plasma concentrations increase exponentially during gestation. They are present at concentrations three times greater than those seen in nonpregnant women and have a long half-life (seven days) postpartum. 


\section{MATERIALS AND METHODS}

After approval from the Institutional Ethical Committee and informed written consent, this prospective randomised study was carried out; 100 patients, women satisfying the inclusion and exclusion criteria were recruited from antenatal \& labourward of Basaweshwar Teaching and General Hospital, Kalburgi, Karnataka. Study Group: Preeclamptic antenatal patients $(n=100)$, Group B: Normotensive antenatal patients $(\mathrm{n}=100) \cdot{ }^{10}$

\section{Inclusion Criteria}

1. Gestational age $>20$ weeks.

2. Primi/Multigravida.

3. Antenatal patients of age 18 - 35 yrs.

4. All antenatal patients are normotensive as well as hypertensive, which do not fall under exclusion criteria.

\section{Exclusion Criteria}

1. Patients with all known renal disease, diabetes, hepatic dysfunction, alcoholism, dyslipidaemia, RH negative blood group and cardiac diseases.

2. Preexisting hypertension before pregnancy except PIH or on any type of anti-hypertensive treatment.

3. Multiple pregnancy.

\section{Collection of Blood Samples}

About $3 \mathrm{~mL}$ of blood was drawn under aseptic precautions from selected subjects in a plain vial for serum. Serum was separated by centrifugation and used for estimation of serum levels of LDH, ALP and UA. Values were calculated as mean \pm SD and the statistical analysis was done using GraphPad Prism V. 6.0 software. Student's unpaired t-test was used for comparison between two groups. The p-value of less than 0.05 was considered as statistically significant. 11

\section{RESULTS}

\begin{tabular}{|c|c|c|c|}
\hline Variables & $\begin{array}{c}\text { Cases } \\
\text { (Preeclampsia) } \\
\text { Mean } \pm \text { SD }\end{array}$ & $\begin{array}{c}\text { Controls } \\
\text { Mean } \pm \text { SD }\end{array}$ & P value* $^{*}$ \\
\hline LDH & $667.9 \pm 31.0$ & $324.4 \pm 82.0$ & 0.001 \\
\hline UA & $4.78 \pm 1.1$ & $4.1 \pm 0.6$ & 0.002 \\
\hline ALP & $322.3 \pm 11.7$ & $241.4 \pm 48.0$ & 0.01 \\
\hline \multicolumn{4}{|c|}{ Comparison of $\mathbf{L D H}, \boldsymbol{U A}$ and $\boldsymbol{A L P}$} \\
\hline
\end{tabular}

\begin{tabular}{|c|c|c|c|c|c|c|c|c|c|}
\hline & & \multirow[t]{2}{*}{$\mathbf{N}$} & \multirow[t]{2}{*}{ Mean } & \multirow[t]{2}{*}{ Std. Deviation } & \multirow[t]{2}{*}{ Std. Error } & \multicolumn{2}{|c|}{$\begin{array}{l}\text { 95\% Confidence } \\
\text { Interval for Mean }\end{array}$} & \multirow[t]{2}{*}{ Minimum } & \multirow[t]{2}{*}{ Maximum } \\
\hline & & & & & & Lower Bound & Upper Bound & & \\
\hline \multirow{4}{*}{ LDH } & Pre-term & 26 & 651.08 & 247.248 & 68.574 & 501.67 & 800.49 & 421 & 1254 \\
\hline & Term & 56 & 628.46 & 333.080 & 62.946 & 499.31 & 757.62 & 231 & 2000 \\
\hline & IUD & 6 & 924.33 & 197.034 & 113.758 & 434.87 & 1413.79 & 743 & 1134 \\
\hline & IUGR & 10 & 748.60 & 397.168 & 177.619 & 255.45 & 1241.75 & 234 & 1298 \\
\hline
\end{tabular}
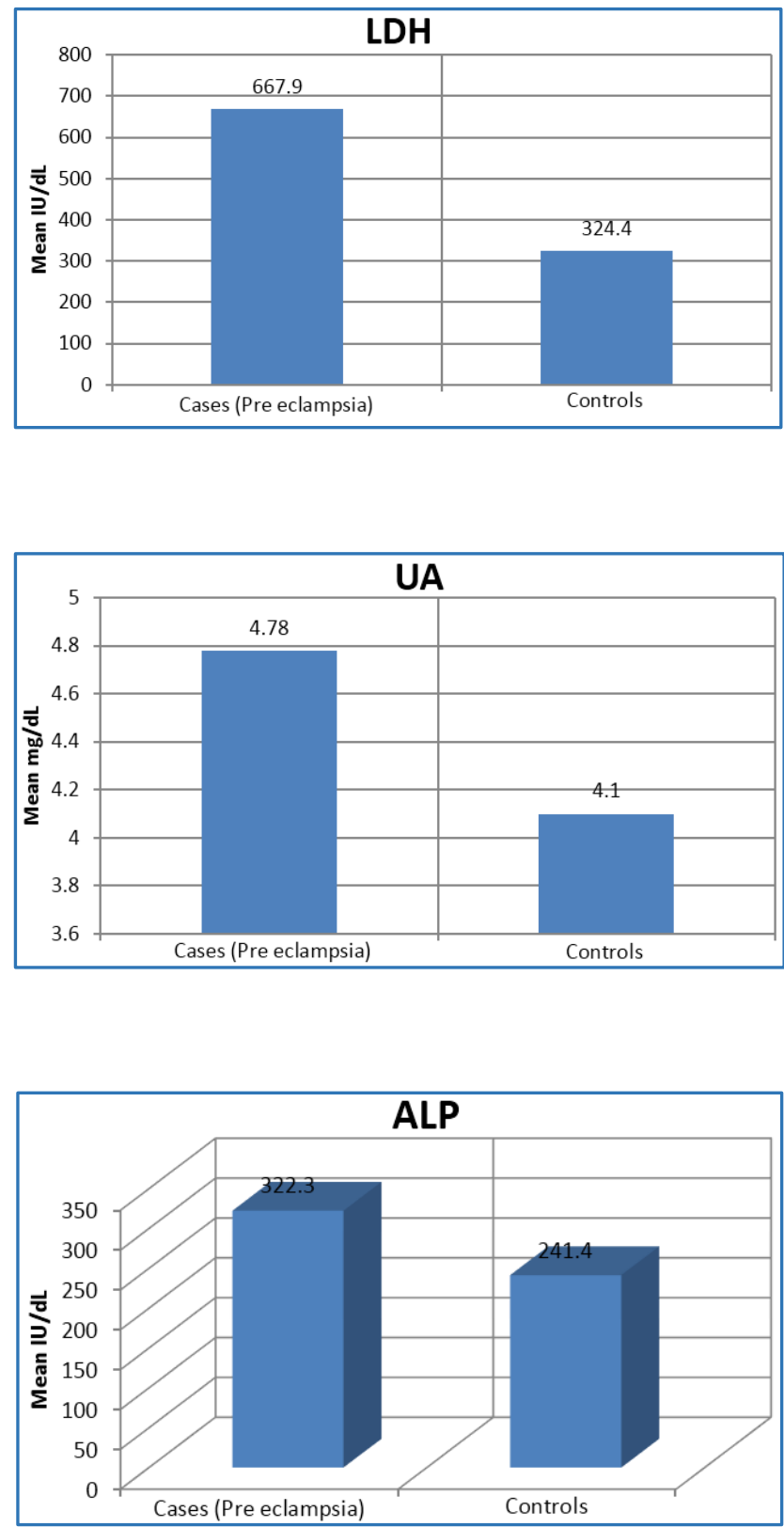


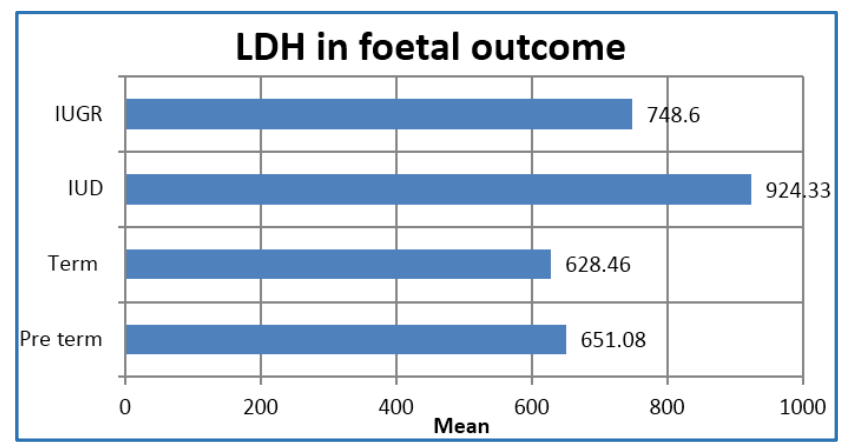

The analysis of LDH levels among preeclamptic cases revealed that the mean LDH was high among IUD babies (924.33) followed by IUGR (748.60), preterm babies (651.08) and term babies (628.46).

\begin{tabular}{|c|c|c|c|c|c|c|c|c|c|}
\hline & \multirow[t]{2}{*}{$\mathbf{N}$} & \multirow[t]{2}{*}{ Mean } & \multirow[t]{2}{*}{ Std. Deviation } & \multirow[t]{2}{*}{ Std. Error } & \multicolumn{2}{|c|}{$\begin{array}{l}\text { 95\% Confidence } \\
\text { Interval for Mean }\end{array}$} & \multirow[t]{2}{*}{ Minimum } & \multirow[t]{2}{*}{ Maximum } \\
\hline & & & & & & Lower Bound & Upper Bound & & \\
\hline \multirow{4}{*}{ ALP } & Pre-term & 26 & 287.62 & 63.975 & 17.743 & 248.96 & 326.27 & 200 & 408 \\
\hline & Term & 56 & 329.14 & 118.348 & 22.366 & 283.25 & 375.03 & 200 & 684 \\
\hline & IUD & 6 & 454.33 & 199.806 & 115.358 & -42.01 & 950.68 & 224 & 581 \\
\hline & IUGR & 10 & 311.60 & 148.440 & 66.384 & 127.29 & 495.91 & 186 & 553 \\
\hline
\end{tabular}

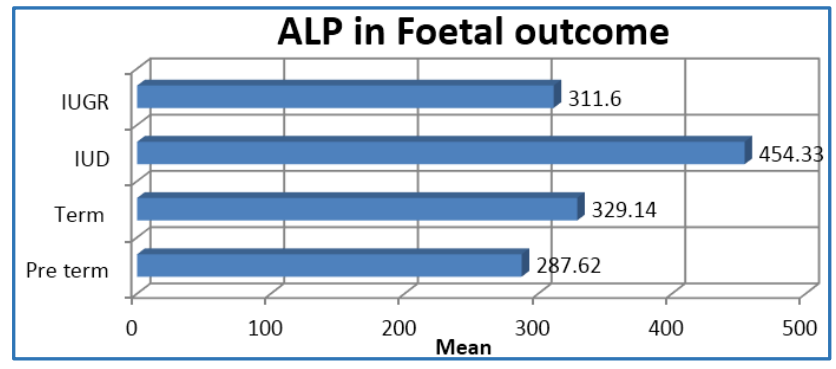

The analysis of ALP levels among preeclamptic cases revealed that the mean ALP was high among IUD babies (454.33) followed by Term babies (329.14), IUGR (311.60) and preterm babies (287.62). ${ }^{12,13,14}$

\begin{tabular}{|c|c|c|c|c|c|c|c|c|c|}
\hline & \multirow[t]{2}{*}{$\mathbf{N}$} & \multirow[t]{2}{*}{ Mean } & \multirow[t]{2}{*}{ Std. Deviation } & \multirow[t]{2}{*}{ Std. Error } & \multicolumn{2}{|c|}{$\begin{array}{c}\text { 95\% Confidence } \\
\text { Interval for Mean } \\
\end{array}$} & \multirow[t]{2}{*}{ Minimum } & \multirow[t]{2}{*}{ Maximum } \\
\hline & & & & & & Lower Bound & Upper Bound & & \\
\hline \multirow{4}{*}{ UA } & Pre-term & 26 & 4.753846 & .9207021 & .2553568 & 4.197471 & 5.310221 & 3.2000 & 6.9000 \\
\hline & Term & 56 & 4.675000 & 1.0193044 & .1926304 & 4.279755 & 5.070245 & 3.2000 & 7.9000 \\
\hline & IUD & 6 & 6.400000 & 2.0420578 & 1.1789826 & 1.327247 & 11.472753 & 4.1000 & 8.0000 \\
\hline & IUGR & 10 & 4.440000 & 1.4380542 & .6431174 & 2.654420 & 6.225580 & 3.0000 & 6.8000 \\
\hline
\end{tabular}

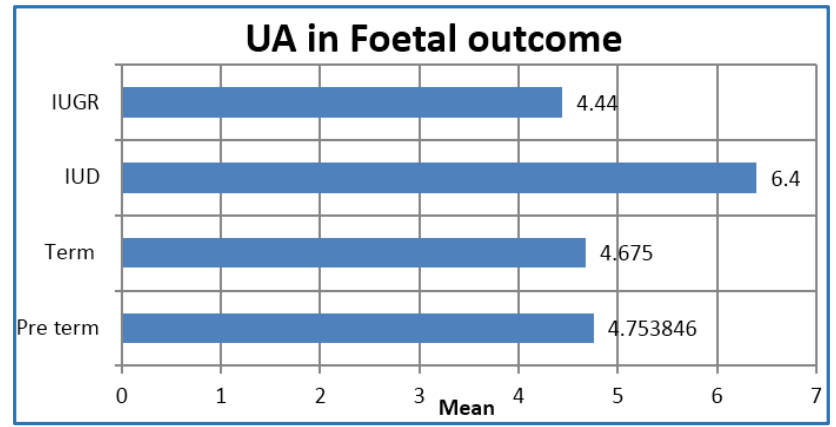

\begin{tabular}{|c|c|c|c|c|c|}
\hline & $\begin{array}{c}\text { Maternal } \\
\text { Complications }\end{array}$ & N & Mean & $\begin{array}{c}\text { Std. } \\
\text { Deviation }\end{array}$ & $\begin{array}{c}\text { P } \\
\text { value }^{*}\end{array}$ \\
\hline \multirow{2}{*}{ LDH } & Yes & 14 & 1006.57 & 293.621 & \multirow{2}{*}{0.001} \\
\cline { 2 - 6 } & No & 86 & 612.35 & 279.424 & \\
\hline \multirow{2}{*}{ UA } & Yes & 14 & 5.857143 & 1.4339423 & \multirow{2}{*}{0.006} \\
\cline { 2 - 5 } & No & 86 & 4.606977 & .9989031 & \\
\hline \multirow{2}{*}{ ALP } & Yes & 14 & 341.14 & 161.912 & \multirow{2}{*}{0.65} \\
\cline { 2 - 5 } & No & 86 & 319.26 & 110.376 & \\
\hline \multicolumn{5}{c|}{$\begin{array}{c}\text { LDH, UA and ALP Levels in Maternal } \\
\text { Complications (Among Preeclampsia Cases) }\end{array}$} \\
\hline
\end{tabular}

The analysis of UA levels among preeclamptic cases revealed that the mean UA was high among IUD babies (6.4) followed by Pre-Term babies (4.7), Term babies (4.6) and IUGR (4.4). ${ }^{15}$ 

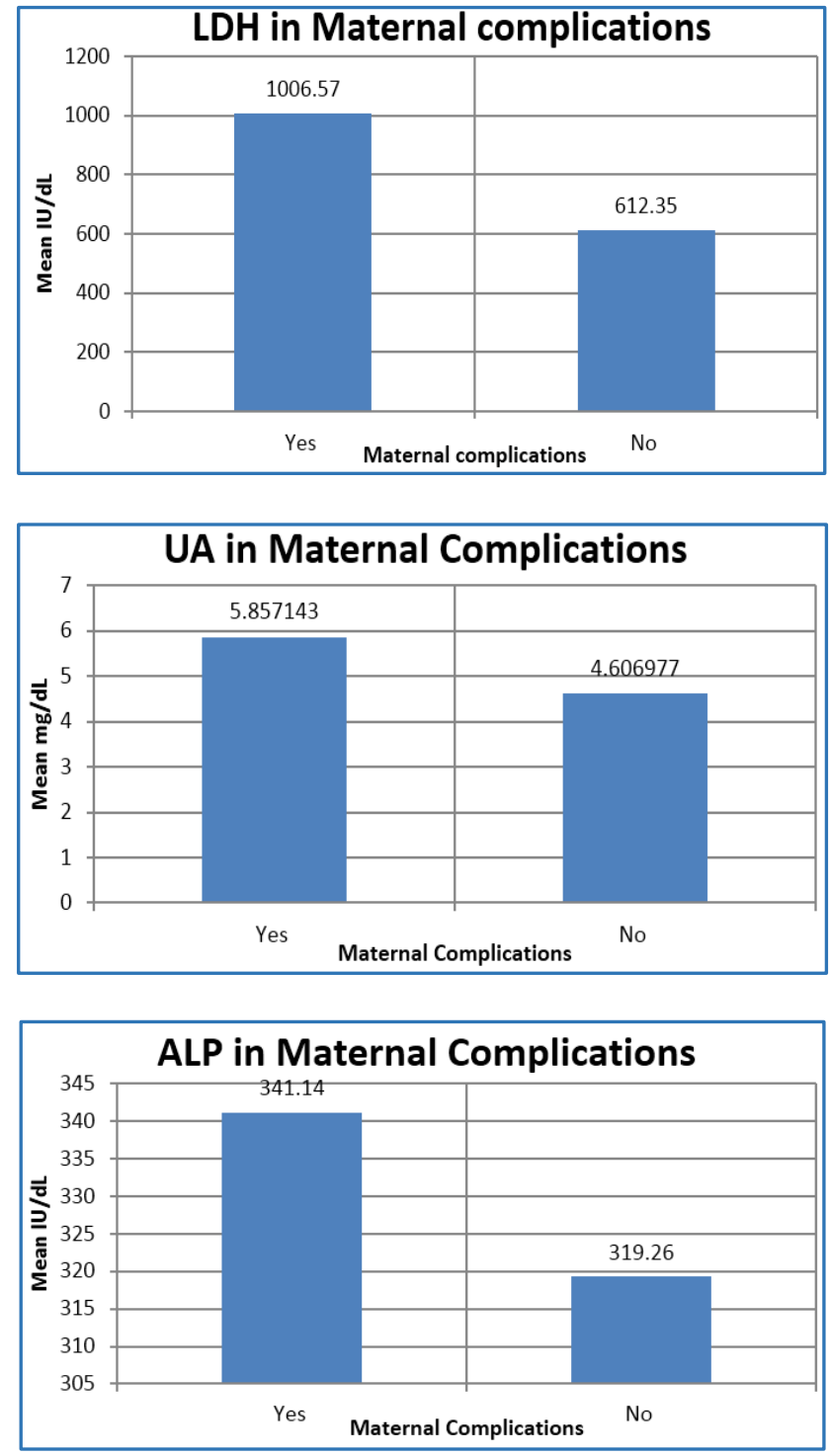

The mean LDH level was high among cases with maternal complications (1006.5) compared to cases without maternal complications (612.35) and this difference is found to be statistically significant. The mean UA level was high among cases with maternal complications (5.8) compared to cases without maternal complications (4.6) and this difference is found to be statistically significant.

The mean ALP level was high among cases with maternal complications (341.1) compared to cases without maternal complications (319.2).

\section{DISCUSSION}

Preeclampsia is a common medical complication of pregnancy. In India, the incidence of preeclampsia is reported to be $8 \%$ $10 \%$ of the pregnancies. It contributes significantly to maternal and foetal mortality and morbidity. Preeclampsia is a multisystem disorder characterised by hypertension to the extent of 140/90 mmHg or more, proteinuria ( $\geq 300 \mathrm{mg} /$ day) and oedema induced by pregnancy after 20 th week. Without intervention preeclampsia progresses to eclampsia; this is characterised by malignant hypertension and epileptiform convulsions requiring emergency caesarean section.

Many theories have suggested that endothelial dysfunction caused by factors released from ischaemic placenta may be a causative factor for disease pathogenesis.
In our study, we have observed a significant increase in serum LDH and uric acid level in women with hypertension in comparison with normotensive women. These findings were in accordance with a study done by Qublan et al and Kozic et al. They concluded that serum LDH can be a useful marker for the prediction of adverse outcome of pregnancy in severe preeclampsia. Serum LDH is also found to be a useful predictor of birth of small for gestational age infants in preeclamptic pregnancy. Previous studies demonstrated the importance of amniotic serum LDH level for the prediction of foetal growth restriction.

It is found that LDH-A (4) isoenzyme is immunolocalised primarily in the foetal endothelial cells, while LDH-B (4) isoenzyme is predominantly present in syncytiotrophoblasts. The LDH-A (4) isoenzyme activity increased approximately by 1.6-fold in preeclampsia when compared with normal pregnancy. This may also suggest that endothelial dysfunction present at uteroplacental vessels can lead to hypoperfusion to the growing foetus and may lead to elevation of LDH isoform.

Hypertensive disorders of pregnancy are commonly associated with a decrease in renal function due to damage done by hypertension and widespread endothelial dysfunction. Glomeruli undergo structural changes with pronounced endothelial cell swelling, vacuolisation and hypertrophy of the cytoplasmic organelles known as "glomerular endotheliosis." The net effects have reduced renal blood flow, reduced GFR, impaired tubular reabsorption and secretory function. In our study, we found that the mean serum UA levels were significantly higher in cases when compared with controls. This finding is in accordance with the study done by Punthumapol et al. It is found that estimation of serum $\mathrm{UA}$ is as important as proteinuria in identifying the risk of renal involvement and foetal compromise. Maternal hyperuricaemia is found to be a strong predictor of maternal disease progression and foetal outcome. Thus, it can be used as a useful and inexpensive marker for predicting disease severity, renal function status and foetal growth retardation in women presenting with HDP. In our study, mean levels of serum LDH and UA were significantly higher in Group A when compared with Group B ( $p<0.05)$. These findings indicate that increased levels of these parameters are seen as the disease severity increases.

\section{CONCLUSION}

We conclude that serum LDH and Serum Uric Acid are reliable and inexpensive markers to predict severity and outcome of hypertensive disorders of pregnancy.

\section{REFERENCES}

1. Qublan H, Ammarin V, Bataineh 0 , et al. Lactic dehydrogenase as a biochemical marker of adverse pregnancy outcome in severe pre-eclampsia. Med Sci Monit 2005;11(8):CR393-7.

2. Kozic JR, Benton SJ, Hutcheson JA, et al. Abnormal liver function tests as predictors of adverse maternal outcomes in women with preeclampsia. J Obstet Gynaecol Can 2011;33(10):995-1004.

3. He S, Bremme K, Kallner A, et al. Increased concentrations of lactate dehydrogenase in pregnancy with preeclampsia: a predictor for the birth of small-forgestational-age infants. Gynecol Obstet Invest 1995;39(4):234-8. 
4. Borna S, Abdollahi A, Mirzaei F. Predictive value of midtrimester amniotic fluid high-sensitive C-reactive protein, ferritin, and lactate dehydrogenase for fetal growth restriction. Indian J Pathol Microbiol 2009;52(4):498500.

5. Tsoi SC, Zheng J, Xu F, et al. Differential expression of lactate dehydrogenase isozymes (LDH) in human placenta with high expression of LDH-A(4) isozyme in the endothelial cells of pre-eclampsia villi. Placenta 2001;22(4):317-22.

6. Haram K, Svendsen E, Abildgaard U. The HELLP syndrome: clinical issues and management. A review. BMC Pregnancy Childbirth 2009;9:8.

7. Guntupalli SR, Steingrub J. Hepatic disease and pregnancy: an overview of diagnosis and management. Crit Care Med 2005;33(Suppl 10):S332-S9.

8. Rahman TM, Wendon J. Severe hepatic dysfunction in pregnancy. Q J Med 2002;95(6):343-57.

9. Joshi D, James A, Quaglia A, et al. Liver disease in pregnancy. Lancet 2010;375(9714):594-605.
10. Punthumapol C, Kittichotpanich B. Serum calcium, magnesium and uric acid in preeclampsia and normal pregnancy. J Med Assoc Thai 2008;91(7):968-73.

11. Roberts JM, Bodnar LM, Lain KY, et al. Uric acid is as important as proteinuria in identifying fetal risk in women with gestational hypertension. Hypertension 2005;46(6):1263-9.

12. Saleh F, Shukar-ud-Din S, Soomro N. Serum uric acid as predictor model for preeclampsia. Pak J Surg 2010;26(3): 246-51.

13. Andrews L, Mehta L, Sharma A, et al. Maternal outcome in relation to biochemical parameters in hypertensive disorders in pregnancy. IOSR Journal of Dental and Medical Sciences 2014;13(2):18-22.

14. Kamath RK, Nayak SR, Shantharam M. Serum Uric acid level in preeclampsia and its correlation to maternal and fetal outcome. Int J Biomed Res 2014;5(1):22-4.

15. Umasatyasri Y, Vani I, Shamita P. Role of LDH (Lactate dehydrogenase) in preeclampsia-eclampsia as a prognostic marker: an observational study. International Archives of Integrated Medicine 2015;2(9):88-93. 